\title{
Why using symbolic computation for proving the convergence of iterative methods?
}

\section{GHEORGHe ARDELEAN and LASZLO BALOG}

\section{ABSTRACT.}

In [YoonMe Ham et al., Some higher-order modifications of Newton's method for solving nonlinear equations, J. Comput. Appl. Math., 222 (2008) 477-486], some higher-order modifications of Newton's method for solving nonlinear equations are presented. In [Liang Fang et al., Some modifications of Newton's method with higher-order convergence for solving nonlinear equations, J. Comput. Appl. Math., 228 (2009) 296-303], the authors point out some flaws in the results of YoonMe Ham et al. and present some modified variants of the method. In this paper we point out that the paper of Liang Fang et al. itself contains some flaw results and we correct them by using symbolic computation in Mathematica. Moreover, we show that the main result in Theorem 3 of Liang Fang et al. is wrong. The order of convergence of the method is'nt $3 m+2$, but is $2 m+4$. We give the general expression of convergence error too.

\section{REFERENCES}

[1] Ardelean, G., A new third-order newton-type iterative method for solving nonlinear equations, Appl. Math. Comput., 219 (2013), $9856-9864$

[2] Ardelean, G., Using symbolic computation in Mathematica for verifying the convergence of the iterative methods, Creat. Math. Inform., 22 (2013), 9-13

[3] Ardelean, G., Proving the convergence of the iterative methods by using symbolic computation in Maple, Carpathian J. Math., 27 (2011), 1-8

[4] Chun, C., Iterative methods improving Newton's method by the decomposition method, J. Comp. and Math. with Appl., 50 (2005), 1559-1568

[5] Dz̃unić, J., Petković, M. S. and Petković, L. D., A family of optimal three-point methods for solving nonlinear equations using two parametric functions, Appl. Math. Comput., 217 (2011), 7612-7619

[6] Fang, L. and He, G., Some modifications of Newton's method with higher-order convergence for solving nonlinear equations, J. Comp. Appl. Math., 228 (2009), 296-303

[7] Gautschi, W., Numerical Analysis: An Introduction, Birkhäuser, 1997

[8] Ham, Y., Chun, C. and Lee, S. G., Some higher-order modifications of Newton's method for solving nonlinear equations, J. Comp. Appl. Math., 222 (2008), 477-486

[9] Petković, M. S. and Petković, L. D., Families of optimal multipoint methods for solving nonlinear equations, Appl. Anal. Discrete Math., 4 (2010), $1-22$

[10] Petković, M. S., Ilić, S. and Dz̃unić, J., Derivative free two-point methods with and without memory for solving nonlinear equations, Appl. Math. Comput., 217 (2010), 1887-1895

[11] Traub, J. F., Iterative Methods for the Solution of Equations, Chelsea publishing company, New York, 1997

[12] Wellin, P. R., Programming with Mathematica, An Introduction, Cambridge University Press, New York, 1999

[13] Wolfram, S., The Mathematica Book, Fourth Edition, Cambridge, ISBN: 9781107009462, 2013

[14] Xiaojian, Z., A note on "Some higher-order modifications of Newton's method for solving nonlinear equations", Appl. Math. Comput., 208 (2009), $14-17$

[15] *** www.wolfram.com/mathematica/

Department of Mathematics And Computer SCience

FACUlty OF SCIENCES NORTH UNIVERSITY CENTER AT BAiA MARE

TECHNICAL UNIVERSITY OF CLUJ-NAPOCA

Victoriei 76, 430122 BAIA MARE, ROMANIA

E-mail address: ardelean_g@yahoo.com

Department of Mathematics And Computer SCIENCE

FACUlTy OF SCIENCES NORTH UNIVERSITY CENTER AT BAIA MARE

TECHNICAL UNIVERSITY OF CLUj-NAPOCA

VICTORIEI 76, 430122 BAIA MARE, ROMANIA

E-mail address: balog_58@yahoo.com

* Dedicated to Professor Emeritus Constantin Corduneanu on the occasion of his 85th birthday

Received: 20.07.2013; In revised form: 01.10.2013; Accepted: 04.10.2013

2010 Mathematics Subject Classification. 65H05, 65-04.

Key words and phrases. Iterative methods, order of convergence, error of convergence, symbolic computation. 